\title{
A descentralização da reforma agrária: algumas notas sobre o cenário brasileiro
}

\section{Considerações iniciais}

Nos últimos anos têm-se evoluído, no âmbito do Estado brasileiro, proposições e, até mesmo, ações concretas em torno da chamada descentralização da reforma agrária como um mecanismo para assegurar a melhoria da qualidade desta política pública, proporcionando, com isso, o acesso à terra pelas famílias de agricultores sem-terras. Paralelamente, percebe-se a crescente orientação no seio dos movimentos sociais de uma perspectiva de desenvolvimento baseado no espaço local, nas potencialidades deste mercado e nas articulações entre os governos, na participação, acompanhamento e controle das políticas pelos organismos da sociedade civil, evidenciando um novo posicionamento dos atores sociais. Para muitos, esta perspectiva caracteriza, igualmente, formas de descentralização das atribuições do poder público.

Este artigo tem como objetivo identificar e analisar alguns pontos do debate recente sobre a descentralização das políticas de reforma agrária, buscando a sua trajetória, bem como as concepções e os interesses colocados em cena pelos atores envolvidos nesse processo.

Neste intuito, o texto apresenta-se dividido em três partes. Inicialmente são explorados alguns elementos da temática da descentralização, buscando a localização da sua emergência no âmbito da discussão sobre a crise do Estado Moderno e a sua conformação na arena política brasileira a partir efetivamente do processo de redemocratização do país. Atentase, igualmente, para os temas recorrentes associados às reflexões sobre descentralização em uma tentativa de se evidenciar a diversidade de situações em que aparece no debate.

Fernando Fleury Curado é mestre em Desenvolvimento Rural e doutorando em Meio Ambiente e Desenvolvimento pelo Centro de Desenvolvimento Sustentável da UnB.

Contato: fcurado@ $\underline{\text { uol.com.br }}$ 
Na seção seguinte, as "notas" são dirigidas ao rural, e nele, às políticas de reforma agrária e às formas e tendências em discussão apontadas para as propostas descentralizadoras. Finalmente, diante das questões identificadas, são reunidos alguns elementos deste debate em uma tentativa de se traçar algumas perspectivas dos rumos do processo de reforma agrária no país.

\section{Como aparece o tema}

A discussão sobre centralização e descentralização não é recente. Alguns estudos dão conta de referências pioneiras em Montesquieu e Tocqueville sendo associadas ao papel do Estado perante a sociedade (Stein, 1997). Duas perspectivas de análise podem ser evidenciadas na intenção de se localizar o tema. Uma delas está relacionada com a crise do Estado Moderno e as vertentes originadas das críticas à forte presença do Estado em determinadas áreas e a (in)capacidade deste organismo em responder a situação de crise financeira e política instalada em muitos países europeus a partir da década de 70 .

A outra perspectiva de análise surge das tendências de descentralização verificadas no Brasil com a inauguração do período de redemocratização e, mais especificamente, com a Constituição de 1988. Trata-se, neste caso, dos efeitos produzidos pelas mudanças nos rumos das funções do Estado ocorridas na Europa diante da situação de crise.

\section{A crise do Estado moderno; a crise do Estado de Bem-Estar Social}

O Estado de Bem-Estar Social significa um dos estágios do ente Estado, “(...) uma extensão e um aprofundamento do Estado-protetor" (Rosanvallon,1997), aparecendo nos países centrais na forma de uma intervenção na economia para salvar o capitalismo da crise mediante a geração de emprego e a recuperação do poder de compra da população. No caso americano, foi resultado da intervenção do Estado após a quebra da Bolsa de Nova York em 1929 (período denominado como a grande depressão). Esta intervenção foi fundamentada pelas idéias de Keynes (1883-1946) e aparece no plano conhecido como New Deal. Para Keynes, "o social (...) é imediatamente compreendido como estruturante interno da dinâmica econômica" (Rosanvallon, op. cit.).

Além da grande intervenção no âmbito social, o Estado de BemEstar Social se caracterizou pela assistência aos cidadãos com base nos seus direitos, e no "(...) reconhecimento do papel formal dos sindicatos" (Stein, op. cit.). Esse movimento de regulação das políticas sociais pelo 
Estado, por outro lado, ocorre como um imperativo ao melhor funcionamento da economia e não apenas no sentido de se atenuar as contradições visíveis em um cenário de crise. ${ }^{1}$

A crise do Estado de Bem-Estar Social representou exatamente a incapacidade do paradigma keynesiano em responder aos fenômenos atuais como o desemprego, o aumento da inflação, o déficit comercial. Um agravante nesta situação de crise foi o choque do petróleo que proporcionou um quadro generalizado de instabilidade econômica no mundo capitalista.

Diante desse quadro, diferentes leituras (e críticas principalmente) aparecem como tentativas de se explicar o comportamento do Estado. Essas leituras vão indicar, igualmente, diferentes projeções sobre os rumos deste ente, além de evidenciar as estratégias necessárias à superação da crise e os interesses específicos que se colocam em cena nas proposições. Tais estratégias impõem-se em um contexto de profundas mudanças tecnológicas, transformações nas relações de trabalho e globalização da economia.

\section{A vertente neoliberal}

Dentre as leituras acerca da crise do Estado Moderno destacam-se aquelas que consideram tal crise como um reflexo da própria forma de intervenção centralizadora, altamente protetora e dispendiosa com que o Estado se apresenta no contexto deste período. Nestas leituras, que congregam a vertente neoliberal, a presença do Estado no mercado deve ser reduzida (Estado Mínimo), permitindo assim a liberdade na acumulação de capitais. Trata-se, portanto, da (re)leitura do liberalismo. Como afirma Draibe (1993:88):

“As 'teorizações' que manejam os assim ditos neoliberais são geralmente emprestadas do pensamento liberal ou de conservadores e quase que se reduzem à afirmação genérica da liberdade e da primazia do Mercado sobre o Estado, do individual sobre o coletivo. E, derivadamente, do Estado Mínimo, entendido como aquele que não intervém no livre jogo dos agentes econômicos".

Neste sentido a vertente neoliberal orienta-se pela crítica ao Estado de Bem-Estar percebido como o maior responsável pela crise econômica. Os princípios norteadores desta vertente, de acordo com Taylor-Gooby, citado por Stein (op.cit.), podem ser reunidos em quatro objetivos políticos:

“1) cortar os gastos públicos; 2) ampliar o escopo do setor privado, a fim de melhorar as opções e retirar a carga do governo; 3 ) destinar aos pobres os gastos estatais remanescentes, passando de serviços 
universais a seletivos; 4) reduzir a tributação, a fim de liberar as empresas, melhorar as opções e apoiar as atividades privadas e voluntárias como substitutas dos serviços previdenciários estatais." (Taylor-Gooby apud Stein, 1997:37).

No conjunto destas orientações é que surgem as tendências à descentralização. Assim:

"Do ponto de vista ideológico, descentralização tem significado, para o campo neoliberal, reduzir o Estado às suas funções mínimas, desregulamentar a economia e privatizar serviços públicos buscando o aumento da eficiência e competitividade geral das economias, para permitir sua inserção no contexto da globalização" (Rodriguez, 1993: 14).

Nos países latino-americanos, estas orientações (além da descentralização, destacam-se a privatização e a focalização) fundamentam os mecanismos de ajustes macroeconômicos que, na maioria das vezes, se materializam a partir de reformas nos programas sociais levados a cabo pelos Estados nacionais e têm, desta forma, ocorrido sobre os auspícios das instituições multilaterais.

\section{A vertente progressista}

Em um determinado momento do Estado de Bem-Estar Social, ocorre o “(...) entrecruzamento de críticas da direita com insatisfações da esquerda" (Rosanvallon, op.cit.: 26). Neste aspecto, a vertente progressista de leituras acerca da crise aponta para a idéia de que este Estado se mostrava comprometido com o "capitalismo avançado". Assim, diferente do que se observava na vertente neoliberal, evidencia-se que o direcionamento às políticas públicas de cunho social demonstrava um mecanismo compensatório, não atuando diretamente nas causas. Além disso, tal vertente analisa que as políticas desenhadas estariam sempre sujeitas às ameaças da crise financeira e o Estado, desta forma, favoreceria a construção de uma idéia falsa sobre a realidade social e política no seio da classe operária. Este seria um fator preponderante na desmobilização desta classe (Offe, apud Stein,1997: 41).

Em outro aspecto, muitas das receitas ou estratégias defendidas por setores de esquerda encontram-se sintonizadas com aquelas da vertente neoliberal. Esta situação acaba por levar à sensação de perda de referenciais analíticos e propositivos diante de um quadro social de exclusão e miserabilidade notadamente encontrado na realidade de muitos países.

No interior desta reflexão é que a descentralização no campo progressista ganha contornos de “(...) democratização do Estado e da 
política, mediante a multiplicação dos centros de poder nas instâncias locais e a procura de aumento da eficiência das políticas pelo controle direto dos usuários" (Rodriguez, op.cit.: 15).

A mesma idéia pode se observada em Rabi, em citação realizada pelo Grupo VI do Projeto Áridas (Aridas; 1994) em que afirma ser a descentralização na visão dos grupos sociais progressistas “(...) a possibilidade da emergência de uma cultura política nova, democrática e participativa que, partindo do Município, pode estender-se em movimento ascendente às demais esferas do Governo (União e Estados)"'(Rabi, apud Aridas, 1994).

Assim a critica ao Estado centralizador característico do Welfare State insurge a perspectiva de valorização do espaço local, da criação de condições institucionais para a organização, acompanhamento e controle das políticas decorrentes da descentralização político-administrativa pela própria população. Neste aspecto, o desenvolvimento local é visto como uma nova dinâmica socioeconômica de gestão do território capaz de potencializar articulações e parcerias entre o poder público e a sociedade em suas formas de organização. Nas palavras de Castells (1998: 09):

"Asi pues, se observa, en el mundo entero, un moviemento de descentralización de las instituciones del estado, en parte respondiendo a reivindicaciones locales y regionales, a expresiones colectivas identitarias, pero en parte también por un esfuerzo consciente del estado nacion de encontrar formulas alternativas a la rigidez de la centralización y a la crisis de legitimidad que emana de la desconfianza de los ciudadanos."

Nenhuma das vertentes resumidamente apresentadas acima se colocam de maneira hegemônica nas críticas ao Estado de Bem-Estar Social. No entanto, demonstram nitidamente a necessidade de se construir novos caminhos na trajetória da relação entre o Estado e a sociedade.

\section{Um novo Estado?}

Na busca de novos caminhos para o Estado e para a sociedade, percebe-se em alguns casos a possibilidade concreta da releitura de antigos paradigmas que ainda se mostram atuais. Um exemplo pode ser notado em algumas recuperações das idéias de Keynes, em torno da tentativa de se fundamentar um outro tipo de Estado, ou mesmo, de se compreender o seu comportamento na atualidade. ${ }^{2}$

No sentido deste debate atual sobre o Estado e a sua crise há uma tendência de se buscar alternativas à visão desestatizante de cunho neoliberal/conservadora, e, da mesma forma, àquelas de cunho anti-neoliberal fundamentada na crítica à crítica ao Estado. É assim que Castells 
parece se dirigir quando propõe a leitura do Estado como um "Estado-

Rede", em que o local e o global estejam conectados em uma rede complexa de articulação dos diferentes níveis institucionais a partir do princípio da flexibilidade que, neste aspecto, garantiria o estabelecimento de um caráter negociador em substituição àquele de Estado decretador (Castells, 1998).

Há, nestas perspectivas de leitura sobre o papel do Estado, sinalizadas até aqui um aspecto unificador que passa exatamente pela negação do fim do Estado, mas pela reorientação deste ente; não pelo seu desmantelamento mas, em outro sentido, pela sua reconstrução (Evans, 1993); não pela desregulamentação, e sim, pela sua (re) regulamentação, ou na (re)estatização (Bursztyn, 1998) e, ainda, na negação da desregulamentação, e pela busca da "reinvenção solidária e participativa do Estado" (Santos, s/d: 16).

Estas tendências de análise, por outro lado, apresentam-se no interior de uma reflexão bem mais complexa e que escapa às possibilidades e aos interesses deste artigo, o que não o exime, ao menos, da sua referência, como uma orientação fundamental para a localização da temática da descentralização em um contexto de reforma do Estado.

\section{Redemocratização no Brasil e a descentralização político-administrativa}

No período de transição democrática, conhecido como Nova República, verifica-se o acontecimento de algumas mudanças tanto institucionais quanto na sociedade brasileira que redefinem a importância do espaço local (configurado no município) nos rumos das políticas nacionais. Entre estas mudanças destaca-se a abertura política que permitiu a emergência de novas forças com as eleições de 1982 e que, naquele contexto, procuravam impulsionar algumas propostas de maior participação popular no âmbito das políticas públicas. Da mesma forma, algumas concepções sobre a descentralização pareciam povoar as principais reivindicações políticoinstitucionais e encontraram o seu ápice na Constituição de 1988. Segundo Rodriguez, “(...) amparada no discurso da democratização, a descentralização financeira da União foi a principal estratégia para quebrar o bunker militar palaciano" (Rodriguez, 1993:14).

\section{A Constituição de 1988}

A trajetória das constituições brasileiras demonstra, segundo o estudo de Leal, citado por Áridas, uma atenção à autonomia do município (Leal, apud Áridas, 1994). Nesta trajetória, com maior ou menor expressão, vai ser exatamente com a Constituição Federal de 1988 que a: 
“(...) unidade municipal de governo passa a ser considerada como a unidade básica do sistema institucional da sociedade brasileira. O município adquire novas responsabilidades e prerrogativas. Transfere-se para eles a prestação de serviços essenciais ao desenvolvimento municipal. A Carta Magna consolida as tendências descentralizadoras já observadas desde a segunda metade da década de 80" (Aridas, 1994:18).

Rapidamente observa-se a criação de novos municípios favorecidos pelo processo de redemocratização. Isso porque, segundo Souza, “(...) no regime militar, as exigências para a criação de novos municípios eram difíceis de serem cumpridas. Mais de 1.000 novos municípios foram criados entre 1975 e 1993"(Souza, 1998:34).

Mais do que a simples criação dos municípios tal movimento representou uma sensível difusão territorial de poder, tanto político quanto financeiro garantida, a priori, pela Constituição Federal de 1988. A partir deste documento, os municípios adquirem o status de esfera de governo com autonomia e competências próprias. Segundo Áridas, nos artigos 29 e 30 da Constituição, são assegurados:

“(...) autonomia política - correspondente à eleição direta do Prefeito, Vice-Prefeito e dos Vereadores; autonomia administrativa - correspondente à liberdade para organizar os serviços públicos locais, criar, organizar e suprimir distritos (observada legislação estadual pertinente) e conceber e executar os órgãos da administração direta; autonomia financeira — correspondente à possibilidade de arrecadar seus tributos e aplicar seus recursos (tributários e de outras fontes) (...); autonomia legislativa — liberdade para legislar no que diz respeito aos assuntos de interesse local, sempre porém, respeitando os limites estabelecidos pela Constituição (...)" (grifos do autor).

A consolidação do fortalecimento dos municípios é percebida nas “(...) disposições tributárias constitucionais”. Diante deste quadro favorável, “(...) os municípios aumentaram em mais de 50\% sua receita, o que significa aproximadamente 8 bilhões de dólares e equivale ao total de gastos estaduais com educação em 1990"(Rodriguez, op.cit.).

Associado às disposições favoráveis ao lugar de destaque assumido pelos municípios, têm-se a notável elevação nas taxas de urbanização do país. Este aumento saltou de $68 \%$ para $74 \%$ somente no período compreendido entre 1980 e 1990 (Souza, op.cit.). Estes fatores em conjunto deram forma a um novo tipo de poder no país, ou seja, o poder local (Stein, op.cit.). 


\section{Tipos de descentralização}

As experiências de descentralização já colocadas em curso nos mais diferentes países mostram que há especificidades marcantes ${ }^{3}$ de acordo com as distintas realidades históricas e políticas. Como vimos, tanto a crise do Estado de Bem-Estar Social como a democratização do Estado permitem a percepção desta tendência nos diferentes países em que é levada a cabo. No caso brasileiro, a redemocratização, a Constituição de 1988 e as reformas estabelecidas a partir de prerrogativas do seu ajuste econômico criaram o ambiente favorável para experiências descentralizadoras mesmo que reservadas a algumas áreas específicas como no campo da saúde.

Considerando tais observações, deve-se ter em vista ainda o ambiente social e cultural conformado em cada caso, bem como a compreensão da centralização e da descentralização como um fenômeno dinâmico, “(...) analisada mais como um continuum do que como dicotomia" (Souza, op.cit.). Da mesma forma Vieira (1971: 77) afirma que:

“(...) a descentralização move-se para cima e para baixo, numa escala contínua cujos extremos resistem a uma definição precisa (...) $\mathrm{O}$ contínuo centralização-descentralização precisa ser estudado globalmente."

Ou ainda:

"Qualquer que seja o sistema político, verifica-se uma influenciação recíproca entre a descentralização e regular número de outras variáveis. Algumas destas são geográficas e históricas; outras, essencialmente econômicas; e ainda outras são demográficas e ecológicas" (idem: 165).

Neste aspecto a descentralização pode ser orientada por interesses distintos assumindo formas e sentidos diferentes na relação que define no interior do Estado, entre as suas esferas, e com a sociedade. De acordo com Lobo, têm-se três vertentes de descentralização: 1) 'horizontal": referindo-se "(...) à passagem de poder às autarquias, fundações, empresas públicas, isto é, àquela praticada no sentido da administração direta para a indireta"; 2) "vertical": ocorre com o “(...) deslocamento do poder entre os distintos níveis do governo, isto é, a transferência do poder federal aos governos estaduais e municipais"; 3) "relação Estado-Sociedade": "(...) caracteriza-se pela transferência de poder do Estado para a sociedade civil (...)", podendo dar-se em duas correntes: a) "comunitarista": "(...) que defende maior articulação entre o Estado e as organizações da sociedade civil no sentido de que estas assumam a execução dos serviços 
técnico-financeiros estatais"; e a corrente "privatista": “(...) que de-

fende a privatização dos serviços públicos, através da venda de empresas públicas ao setor privado lucrativo" (Lobo apud Stein, op cit.: 69 e 70 - grifos da autora).

Draibe, por outro lado, parece situar a descentralização do tipo comunitarista também no campo da privatização. Para a autora, trata-se de uma outra forma de privatização “(...) que propõe o deslocamento da produção e/ou da distribuição de bens e serviços públicos para o setor privado não-lucrativo, composto por associações de filantropia e organizações comunitárias, ou as novas formas de organizações não-governamentais" (Draibe, op. cit.: p. 93).

Indiferentemente das tentativas rígidas de caracterização da descentralização em modelos pré-determinados, o que demonstra estar aparente nestas observações é que tal processo pode assumir, como vimos, formas e interpretações distintas e, por vezes, complementares, exigindo um olhar mais atento nos casos e nas situações em que se manifesta.

\section{Associações do tema no plano político}

Além das distintas formas em que se pode apresentar a descentralização, são vastas as possibilidades de associação do tema com outras temáticas, o que aponta para a complexidade de sua análise. No plano político são mais comuns as associações à democracia e autonomia, entre outras.

\section{a) Democracia}

Há, em muitas leituras acerca das ações descentralizadoras, a idéia de que tais ações refletem necessariamente o caráter democrático como um componente implícito destas experiências. Assim, nesta concepção, o fato de ocorrer a transferência de responsabilidades do Estado para a sociedade representaria, em si mesma, a garantia da efetivação de práticas democráticas pelos governos locais.

Em outra perspectiva se colocam aqueles que percebem o equívoco da associação direta sem outro nível de reflexão, ou seja, da idéia de que nem toda prática descentralizadora significa a emergência da democracia. Como afirma Vieira:

"A descentralização costuma emergir como o pólo positivo, ao qual se associam valores como liberdade individual e autogoverno democrático, em contraposição à centralização, considerada o pólo negativo, geralmente associado com o totalitarismo e autocracia (...) Há necessidade de estudar quais os fatores ligados à descentralização 
que possam levar à democracia, e não simplesmente pressupor que a

descentralização, por si mesma, seja suficiente para assegurar a existência de instituições democráticas" (Vieira, op. cit.: 76 e 77).

Na mesma direção Pereira vai afirmar que esta associação direta entre democracia e descentralização somente pode ser efetivada à medida que contemplar “(...) a intermediação da participação popular e do controle social, que pressupõe a intermediação das divergências sociais como um instrumento da lógica democrática". (Pereira, apud Stein, op. cit.: 22)

\section{b) Autonomia}

Como vimos anteriormente, a descentralização pode envolver a relação entre esferas do governo local as quais não se posicionam com a mesma parcela de poder na arena política. Isso significa afirmar que a descentralização a priori não proporciona necessariamente autonomia aos espaços locais e, portanto, tal associação deve ser alvo de maiores atenções e análises quando remetidas às realidades dos campos específicos em que se consolidam tais experiências. Isso porque como afirma Vieira (op. cit.: 79):

"Um governo central pode exercer controle sobre as unidades descentralizadas de diversas maneiras inter-relacionadas, compreendendo desde o poder de rever algumas ou todas as decisões locais até a prerrogativa de criar, modificar ou mesmo extinguir as unidades descentralizadas e bem assim determinar a respectiva competência."

A própria difusão do poder segundo Tobar consiste na criação de autonomias. No entanto, é preciso que se identifique os atores envolvidos na transferência do poder decisório, e seus detentores no intuito de se verificar se os valores reconhecidos no exercício deste poder têm sua origem fundamentada em uma perspectiva transformadora ou, em outro sentido, calcada em forças conservadoras e reacionárias (Tobar, apud Stein, op. cit.).

No interior deste debate surge uma confusão recorrente nas teorizações sobre as relações intergovernamentais em processos descentralizantes. Trata-se da utilização dos termos desconcentração e descentralização como representantes de um mesmo significado.

As tentativas de se evidenciar a diferenciação entre os termos citados parecem ter sido ancoradas na difusão do poder que se estabelece em processos de mudança no papel dos governos locais. Desta forma, na descentralização, junto com a transferência de funções e de competências, ocorre a distribuição de poder. "As unidades locais são criadas com poderes próprios para administrar certos campos de atividade em que podem usar iniciativa e discernimento próprios" (Vieira, op. cit.: 80). 
No caso da desconcentração não há a distribuição de poder do centro para as unidades locais, sendo transferidas as funções e competências, ambas sob o comando do primeiro. Nesta situação: “(...)o poder central cria unidades administrativas ou órgãos locais, isoladamente ou formando uma hierarquia, e determina o que podem e como o devem fazer (...) tem por objeto descentralizar a execução dos serviços" (idem).

Ainda sobre a dimensão da autonomia no campo político, pode-se indagar sobre as possibilidades de perda da governabilidade com o processo de descentralização. Na realidade da descentralização brasileira, percebese um movimento de alteração na capacidade governativa diante da “(...) fragmentação nas relações intergovernamentais no país” (Souza, op., cit.: 32). Em determinadas situações, a descentralização pode indicar o enfraquecimento ou mesmo a perda da governabilidade. Para Rodriguez, (op. cit.: 15) no caso brasileiro:

"O enfraquecimento das burocracias estratégicas e das agências reguladoras estatais ampliou o clientelismo e o grau de incerteza na formulação e implementação das políticas. A descentralização, em lugar de aumentar a eficiência e a transparência, enfraqueceu a capacidade governativa do sistema político".

Em outro sentido, Dowbor afirma que a descentralização se coloca como um mecanismo favorável ao direcionamento dos esforços do governo central para a resolução de questões de ordem mais gerais aos interesses do Estado. Nas palavras do autor:

“(...) quando o governo central se vê entulhado por milhares de pequenos pedidos locais, passa a gerir interesses fisiológicos em vez de governar o país, ocasionando a perda de governabilidade (...) Apenas descentralizando de forma decidida, poderá a União "limpar a mesa" de milhões de pequenas causas e problemas burocráticos, e se concentrar no que efetivamente devem ser as suas preocupações: os equilíbrios macro-econômicos, os desequilíbrios regionais, os grandes equilíbrios sociais, as políticas tecnológicas de longo prazo, (...) a inserção do país no espaço econômico internacional" (Dowbor, 1994).

Tal perspectiva, por outro lado, parece não fornecer as devidas proporções ao significado do fortalecimento dos governadores ou dos prefeitos com a descentralização político-administrativa. $\mathrm{O}$ fortalecimento destes atores segundo Lobo: 1) fornece os instrumentos para que governem mediando relações sociais e, com isso, articulem interesses e processem demandas; 2) permite que tenham "importante influência sobre os congressistas (...)" e 3) permite que tenham “(...) bases políticas e eleitorais nos planos local 
e estadual" e, portanto, desempenhem “importantes papéis nos processos de eleições” (Lobo, apud Aridas, 1994: 20).

As características do poder destes governantes se por um lado pode desafogar o governo central pode, em outro sentido, ser um elemento a mais na definição do jogo de forças políticas que possam garantir a governabilidade do país. Como observa Souza (op. cit.: 32):

"Na ausência de uma orientação política baseada nos postulados dos partidos, os políticos subnacionais, especialmente os governadores dos estados mais poderosos e os prefeitos dos municípioscapitais, passaram a ser um dos principais atores no sentido de fornecer ao governo federal coalizões que lhe permitam condições de governar."

\section{Associações do tema no plano administrativo}

\section{a) Estadualização}

Ao se tratar da descentralização, torna-se possível observar a associação no plano administrativo ao corte espacial territorial que concede a transferência de atribuições aos Estados em uma perspectiva de "recuperação do federalismo" com o fortalecimento dos Estados (Stein, op. cit.). Tal orientação parace ser menos recorrente no conjunto dos trabalhos relacionados com o tema da descentralização.

\section{b) Municipalização e prefeiturização}

De acordo com a Carta de Brasília, citada por Áridas, a descentralização deve ocorrer mediante a transferência de poder do nível de governo central para os níveis descentralizados, ou seja, Estados e municípios. Assim a municipalização:

“(...) não representa a mera determinação ao Governo Municipal de responsabilizar-se pela prestação de serviços, mas deve significar a efetiva mobilização dos agentes do Poder Local - Governo, comunidade e empreendedores privados - para atuarem no sentido de efetivar a oferta do serviço, garantindo o controle social sobre sua prestação e o interesse público" (Carta de Brasília, apud Aridas op. cit.: 20).

A amplitude deste conceito favorece, comumente, a realização de referências ao que, na realidade, corresponde à chamada "prefeiturização", por vezes tomada como sinônimo de municipalização. Stein citando Sposatti afirma que a idéia contida no termo prefeiturização está mais associada a 
um “(...) localismo restrito, no reforço da administração por convênios e na pulverização de recursos e exacerbação de clientelismo" (Sposatti, apud Stein, op. cit.).

\section{A descentralização da política de reforma agrária no Brasil}

Apesar do caráter marcadamente indicador de uma tendência descentralizadora das políticas públicas, a Constituição Federal de 1988 não trata da descentralização das políticas agrárias. No entanto, percebese - principalmente nos últimos dois anos - a tentativa crescente de construção de arranjos institucionais, tendo em vista atender aos interesses locais em torno da reforma agrária. Este movimento tem sido mais intenso a partir da percepção do próprio governo central, da sua incapacidade histórica na regulamentação desta política.

A seguir, tentaremos localizar o aparecimento da temática da descentralização no debate sobre as políticas de reforma agrária, abordando as ações neste sentido e as tendências e perspectivas colocadas diante das possibilidades da sua efetivação no agronacional.

\section{$O$ contexto das políticas de reforma agrária no cenário recente}

Já vem de longa data o debate sobre a reforma agrária no Brasil. Certamente em todas as suas manifestações evidenciam-se interesses distintos, dando contornos quase sempre acalorados às discussões. É exatamente a partir do período de redemocratização do país e do estabelecimento do processo de elaboração de sua Constituição que o tema passa a adquirir outros elementos e a refletir mais acentuadamente a necessidade de uma presença mais efetiva do Estado na realização da reforma agrária.

Em relação às propostas de colonização do período de governo sobre o regime militar há, portanto, no contexto da redemocratização, um sensível incremento na criação de assentamentos rurais ${ }^{4}$ em diferentes regiões do país. Menos por interesse direto do Estado, estes assentamentos surgiam do acirramento dos conflitos no campo já latentes e resultantes da organização das diferentes facetas do movimento social no campo. ${ }^{5}$ As tentativas de formulação de propostas que resolvessem a questão da elevada concentração fundiária no país, como o I Plano Nacional de Reforma Agrária (PNRA), mostraram-se rapidamente frustradas. Associam-se a isto as constantes alterações que foram submetidas às instâncias do governo que se apresentavam envolvidas com esta política. Criações e extinções de órgãos e ministérios, transferências de atribuições, 
enfraquecimento e desmantelamento do Incra, entre outras ações, têm sido

a tônica da presença do poder público ao longo destas duas últimas décadas.

No decorrer deste período, como apontado, novos termos e atores apareceram no debate. O aumento do número de assentamentos, a crescente demanda por mais terra por parte do enorme contingente de famílias expulsas do campo pela "modernização conservadora", além do inchamento das cidades e do aumento das taxas de desemprego urbano e rural, enfim, todos estes fatores levaram a uma maior atenção para as condições necessárias à viabilidade econômica dos projetos de assentamentos. A visibilidade e a territorialidade conquistada pelo Movimento dos Trabalhadores Rurais Sem Terra (MST) e o avanço nas mediações do Movimento Sindical dos Trabalhadores Rurais (MSTR) nas ocupações de terra foram sensíveis ao Estado, exigindo novas formas de atuação na reforma agrária.

Mais recentemente tanto na esfera normativa como no rito sumário das desapropriações, ou nas mudanças no Imposto Territorial Rural (ITR), quanto na esfera institucional, a partir da criação do Ministério Extraordinário da Política Fundiária (atual Ministério do Desenvolvimento Agrário), têm-se o incremento no assentamento de famílias de agricultores. Este incremento resulta-se igualmente das constantes pressões exercidas pelo movimento de luta pela terra (Garcia Jr, op. cit.) ao governo federal. Somam-se a tais demandas o desafio de se construir estratégias de internalização da dimensão ambiental na estrutura organizativa do Estado, bem como favorecer as articulações e parcerias no âmbito dos governos locais em relação às políticas de assentamento.

\section{Origem e trajetória da descentralização na reforma agrária}

Em certa medida as experiências de descentralização de políticas sociais levadas a cabo em alguns municípios com as prerrogativas advindas da Constituição de 1988, contribuíram para a formulação das referências iniciais de descentralização da reforma agrária. Antes mesmo, com a Nova República e os governadores eleitos em 1982, já se percebia algum direcionamento por parte dos Estados, fato este que permitiu a criação de alguns poucos assentamentos e, institucionalmente, possibilitou a criação de órgãos de terras que, não obstante a ausência de desapropriações, tinham o poder de promover regularizações fundiárias (Medeiros, 1994).

Em meados desta década alguns acontecimentos marcantes ocorridos no cenário da luta pela terra como o massacre de trabalhadores rurais sem-terra em Corumbiara/RO, e em Eldorado dos Carajás/PA, tiveram repercussão internacional, exigindo maior atenção do poder público, 
alterando até mesmo sua forma de interlocução com o MST, e (re) redimensionando a questão agrária no conjunto das políticas do governo. Neste contexto é criado, em fins de abril de 1996, o Ministério Extraordinário de Política Fundiária e, no bojo da retomada do debate, ocorre a formulação de algumas propostas como a desapropriação de terras pertencentes a devedores do Banco do Brasil (Jornal O Popular 28/04/96) e terras penhoradas pelo INSS (Jornal O Popular, 16/04/97), a liberação de mais recursos para os assentamentos e novas formas de acesso à terra como o programa Cédula da Terra, ${ }^{6}$ e a descentralização do processo de reforma agrária com a participação dos Estados e municípios em ações como o Projeto Casulo ${ }^{7}$ (Jornal O Popular 26/03/97), entre outras propostas (Curado, 1998).

A gradativa abertura dos Estados e, principalmente, dos municípios na participação nas políticas de reforma agrária encontra significado em dois aspectos essenciais: o primeiro está relacionado com os impactos regionais proporcionados por algumas experiências de assentamento de trabalhadores rurais em que se percebia claramente o aumento na circulação de recursos financeiros, o incremento do comércio e do restante da economia local. Este elemento permitiu, em algumas localidades, um comportamento mais "cordial" dos prefeitos e demais autoridades políticas locais no sentido do favorecimento ao acesso aos serviços públicos municipais pela população assentada. Não restam dúvidas, porém, de que relações clientelísticas foram fortemente estabelecidas nas mediações de prefeitos e vereadores bem intencionados.

O segundo aspecto tem a ver com a destinação dos recursos externos para a reforma agrária por Instituições Financeiras Multilaterais (IFMs) como Banco Mundial (Bird), e o Banco Interamericano de Desenvolvimento (BID). ${ }^{8}$ A circulação de informações acerca da possibilidade de acesso a recursos financeiros direta ou indiretamente tem se apresentado como um importante elemento explicador para o pretenso interesse de muitos prefeitos e governadores ${ }^{9}$ pela reforma agrária.

A principal tônica das propostas de ação do então Ministério Extraordinário de Política Fundiária, desde a sua criação, e do atual Ministério do Desenvolvimento Agrário tem sido em torno da descentralização da reforma agrária. Nos discursos iniciais do representante da pasta já se percebe que a desapropriação surge como um dos elementos das atribuições a serem transferidas para os governos estaduais ${ }^{10}$ o que exigiria a alteração na Constituição Federal.

A substituição na presidência do Incra em 1997 significou um novo impulso nas proposições pela descentralização, perfeitamente assumidas pelo seu representante nos fóruns de discussão com os governadores e secretários de agricultura dos governos locais. ${ }^{11}$ 
Ainda em 1997, a Medida Provisória no 1.577 editada no mês de junho traz os principais elementos para a descentralização. Para sua efetivação, seria necessária inicialmente a criação do Conselho Estadual de Reforma Agrária, ${ }^{12}$ bem como o estabelecimento de parcerias entre os governos estadual e federal e a transferência de certas atribuições a Estados e municípios. Entre as atribuições estão o cadastro rural, a vistoria e avaliações de terra, a desapropriação de imóveis, a criação de projetos de assentamentos, a regularização fundiária, e, até mesmo, a seleção de famílias para o assentamento. Cada atividade citada seria atribuída diferentemente entre o Incra, o Estado, municípios e o Conselho Estadual de Reforma Agrária, excluindo um ou outro em algumas delas (Jornal O Popular, 06/10/97).

Outro aspecto que favoreceu os rumos do debate sobre a descentralização foi a internalização dos resultados positivos alcançados em algumas regiões pelo Programa Nacional de Fortalecimento da Agricultura Familiar (Pronaf), que propõe a gestão descentralizada da política de desenvolvimento rural, envolvendo as esferas federal, estadual e municipal, juntamente com as representações da sociedade civil. A influência deste programa pode ser visualizada nas recentes mudanças nas propostas de políticas de reforma agrária com a unificação das políticas de Agricultura Familiar e Reforma Agrária no âmbito dos Projetos de Assentamento, conhecido como "Agricultura Familiar, Reforma Agrária e Desenvolvimento Local para um Novo Mundo Rural". ${ }^{13}$ A unificação destas políticas ganha corpo institucional com a criação do Ministério do Desenvolvimento Agrário.

\section{Principais questões da descentralização da reforma agrária}

\section{As posições dos atores}

Os principais atores do processo de reforma agrária, o MST e o MSTR (por meio da Confederação Nacional dos Trabalhadores na Agricultura - Contag), têm se colocado de forma atenta nos desdobramentos das propostas descentralizadoras advindas do governo central. $\mathrm{O}$ posicionamento destes atores tem sido um dos entraves à efetivação deste processo, deixando à mostra que se trata mais da manifestação dos interesses do governo federal do que de uma demanda das organizações locais.

As preocupações com a concepção da proposta e com a forma de distribuição das atribuições, além do controle social, e a coordenação do processo representam os principais pontos de questionamento do movimento sindical. O MST, por outro lado, tem se mostrado totalmente contrário às 
experiências de descentralização e negando-se, inclusive, em algumas situações, ao estabelecimento do diálogo com os governos locais.

Para o movimento sindical “(...) a descentralização deve estar norteada na necessidade de se promover o desenvolvimento rural baseado no fortalecimento da agricultura familiar" (Contag, s/d). Neste sentido propõe, entre outros aspectos, a institucionalização da participação da sociedade civil, a fim de garantir o controle social, a garantia da coordenação do processo pela União, a continuidade da competência para realização de desapropriações junto ao governo federal e a definição prévia das atribuições nos níveis de governo (idem).

\section{O orçamento da União}

Os mecanismos utilizados na definição da forma de orçamentação realizada pelo governo federal remete às dúvidas quanto a “(...) flexibilização necessária na aplicação de recursos, num processo de descentralização" (Buarque, 1997: 17). Este aspecto está fundamentado na recorrente prática do Executivo em promover de forma absolutista o desvirtuamento de muitas políticas (Oliveira, 1997). Segundo Furtado \& Goiás, “(...) o executivo não favorece o debate público, onde as diretrizes e as prioridades da sociedade, aflorados livremente, deveriam condicionar a elaboração da proposta orçamentária" (Furtado \& Goiás, 1994: 8).

Diante desses elementos abordados, a descentralização da reforma agrária representaria meramente uma descentralização na execução e não nas decisões, permanecendo assim, a mercê de uma prática orçamentária bastante centralizadora.

\section{A complexidade da reforma agrária}

A realização da reforma agrária como política pública está permeada por distintas fases definidas pelo Estado e que partem da regularização fundiária, implementação do projeto de assentamento, sua consolidação e, finalmente a sua emancipação. Nestas fases há sempre a inter-relação das políticas fundiária, de crédito, assistência técnica até as de cunho social como habitação, saúde, educação, e que conferem, no conjunto, a complexidade do processo de reforma agrária (Bacelar, 1997).

Esta característica pode representar um entrave à descentralização quando não há o devido entendimento — no âmbito dos governos locais — das dimensões deste processo, ou ainda, quando as atribuições são transferidas abruptamente, de forma fragmentada, sem a participação da sociedade civil e, desta forma, sem a devida internalização dos meios para sua efetivação pelos atores sociais envolvidos neste processo (idem). 
Estados e municípios e a reforma agrária

Apesar dos aspectos já levantados anteriormente sobre a abertura dos Estados e municípios em relação à participação nas políticas de reforma agrária, a ausência de tradição destes níveis de governo ainda é considerado um complicador para a descentralização (Bacelar, op. cit.). Em muitas regiões do país, a reprodução de relações de clientelismo, mandonismo e coronelismo pela elite local se apresentam camufladas por propostas democráticas.

Nestes locais ainda se observa o sentimento de repúdio aos assentamentos de reforma agrária advindos dos grandes proprietários que representam, na maioria das vezes, a base de sustentação política de prefeitos e vereadores. Este fator tem sido o principal argumento das lideranças do MST contra as tentativas de estadualização da reforma agrária em algumas regiões.

\section{O estigma da incapacidade do governo federal}

A trajetória das propostas de descentralização por parte do governo federal é, como vimos, marcada por discursos que se modificam aos passos da sua evolução e da disseminação deste debate junto aos atores envolvidos. Por outro lado, ainda é muito presente no discurso oficial a idéia de "desobrigação" diante da incapacidade de lidar com a questão agrária. Isso é notado nas declarações por parte do poder público federal sobre os altos custos desta política, da necessidade de prerrogativas para a desapropriação pelos Estados, e, principalmente, na falta de clareza na informação dos seus interesses e dos objetivos da descentralização.

Este comportamento faz que, por vezes, se acredite na redução dos gastos com a difusão das atribuições e responsabilidades, bem como na possibilidade da emancipação dos assentamentos criados. Em outras situações, acredita-se que o real objetivo está na mera agilização da reforma agrária. Mais recentemente parece se mostrar associada ao fortalecimento da agricultura familiar, assumindo uma perspectiva mais macro que, em um olhar mais atento, se aproxima bastante das propostas do movimento sindical.

Seja como for, é perceptível ao longo da evolução deste debate a existência de alguns sinais de propostas do movimento sindical nas formulações do governo, o que pode ser salutar no amadurecimento das estratégias não em torno da descentralização do processo de reforma, mas sim como tem se posicionado alguns - da descentralização das ações de apoio à reforma agrária. 


\section{Considerações finais}

A temática da descentralização tem permeado várias políticas públicas no cenário brasileiro em decorrência, por um lado, das experiências dos países europeus fundamentadas nas críticas ao Estado de Bem-Estar Social e, por outro, do período de redemocratização nacional que encontra o seu ápice na Constituição Federal de 1988.

Deste período para o momento atual, tem sido intenso o debate e algumas ações concretas principalmente no campo das políticas sociais (educação, seguridade social, saúde), aumentando sensivelmente o poder político dos governos locais, redimencionando a participação e o desempenho financeiro dos municípios.

As reflexões sobre a descentralização apontam para a complexidade de leituras sendo descritas diferentes associações a outros temas como: democracia, autonomia, participação, cidadania, desconcentração, estadualização, municipalização, prefeiturização, entre outros.

No interior deste debate surge recentemente no cenário brasileiro proposições em torno da descentralização da reforma agrária, assumindo diferentes nuances mas, gradativamente, sendo internalizadas na pauta de discussões entre governos locais e dos demais atores envolvidos no processo.

Os desafios para a implementação da efetiva descentralização da reforma agrária ainda são sensíveis. Por outro lado, os interesses do governo federal (e daqueles que financiam suas políticas), apesar das constantes alterações no discurso oficial, parecem indicar, no limite, uma forte disposição para negociar a qualquer custo a difusão das atribuições na reforma agrária. Neste processo deve-se garantir a efetiva participação da sociedade civil neste debate, bem como o acompanhamento e o controle social destas políticas como ingredientes primordiais na construção do ambiente social favorável para a realização da reforma agrária no país.

\section{Notas}

Nas palavras de Rosanvallon “(...) Keynes ultrapassa, no estrito plano da teoria econômica, o velho antagonismo entre (...) progresso social e eficácia econômica (...)” (Rosanvallon, 1997: 40).

2 Sobre a atualidade do keynesianismo ver: Bursztyn, M. (1991), "Regular o Estado". Revista Raízes, o 8, UFPb, Campina Grande, jan./dez.; ou ainda: Krugman, Paul. (1997), Vendendo Prosperidade: sensatez e insensatez econômica na era do conformismo. São Paulo: Ed. Campus. 
3 Uma rápida incursão na análise das experiências de descentralização em países como a França, Itália, Espanha, Bélgica e Estados Unidos aparece no estudo de Stein, já citado neste texto (Stein, op. cit.). Outra referência - neste caso mais antiga - é o estudo de Vieira envolvendo 45 países (VIEIRA, Paulo Reis. (1971), Em busca de uma teoria de descentralização: uma análise comparativa em 45 países. Rio de Janeiro:FGV).

4 Segundo Garcia Jr. et al, o termo assentamento tem sua origem no âmbito do Estado em meados dos anos 60 sendo usado, sobretudo, como “(...) forma oficial de designar o processo de transferência e de alocação de grupos de indivíduos e de famílias em algum imóvel rural específico (...)" (GARCIA Jr., et al. (1997), "Assentamentos Rurais em perspectiva comparada: uma análise das dimensões econômica, social, histórica e ambiental". Debates CPDA, Rio de Janeiro: UFRRJ/CPDA, no 4, dez.

5 Sobre as diferentes formas de movimentos sociais que surgem no campo neste período ver: Grzybowski, Cândido. (1987), Caminhos e descaminhos dos movimentos sociais no campo. Rio de Janeiro:Fase.

6 O programa Cédula da Terra é parte de uma proposta de reforma agrária desenvolvida pelo Banco Mundial em outros países da América Latina, tendo como orientação básica “(...) a garantia de carta-de-crédito para grupos de agricultores sem terras que desejem efetivar a compra de uma determinada área e financiamento de infra-estrutura coletiva, produtiva e social" (Instituto TeоTôNIO VILELA. (1998), Reforma Agrária: uma questão social e moral. Brasília, p. 39).

7 O projeto Casulo “(...) é um projeto de descentralização e execução da reforma agrária, através do cadastramento de agricultores sem terras e identificação de áreas públicas municipais e estaduais disponíveis para a compra". Trata-se de uma parceria em que o governo federal garante créditos e assume com municípios e Estados o financiamento para a infra-estrutura. (Instituto Teotônio Vilela, op. cit.: 40).

8 No final do primeiro trimestre de 1997, por exemplo, o Banco Interamericano de Desenvolvimento (BID) anunciava a liberação de 150 mil dólares para a reforma agrária no Brasil. Este recurso seria destinado para a criação de novos assentamentos e a recuperação dos já existentes. Jornal O Popular, Goiânia, 04/03/97).

9 Como afirma Vianna Jr., muito menos pelo montante de recursos investidos pelas IFMs no Brasil a importância destas agências “(...) é mais do que a decorrente de seu papel como agentes financeiras, mas o de instituições que colaboram decisivamente na formulação de políticas e projetos do Governo brasileiro" (VIANNA JR., Aurélio. (1997), "O financiamento e a "inteligência": a importância das Instituições Financeiras Multilaterais do Brasil". Informativo Inesc, Brasília, no 79, out., p. 9.

${ }^{10}$ No discurso do Ministro Raul Jungmann “(...) não há razão para os governos estaduais não promoverem desapropriações" (Jornal O Popular, Goiânia, 22/03/97).

${ }^{11} \mathrm{Na}$ defesa da descentralização da reforma agrária, o então presidente do Incra Milton Seligman assim se expressa: “(...) Queremos tirar o processo de Brasília, firmar parcerias com governos estaduais, prefeituras e os trabalhadores" (Jornal O Popular 19/07/97). Ou ainda: "Sozinho o Incra é absolutamente ineficiente para tocar o programa de reforma agrária, embora tenha sido eficaz na missão de retirar da miséria aqueles que conseguem ser incluídos no projeto" (Jornal O Popular 25/11/97).

${ }^{12}$ Dois Conselhos são criados inicialmente em regiões com problemas históricos de conflitos por terra, ou seja, Sul do Pará, e no Pontal do Paranapanema, no Estado de São Paulo. No Estado de Goiás, a tentativa de criação do Conselho encabeçada pelo titular do órgão de terras estadual e pelo superintendente regional do Incra foi palco de profundas críticas pelos movimentos sociais, funcionários do órgão, e, até mesmo, por alguns parlamentares do próprio partido da situação. Não se dispõe de informações sobre a proposta da criação do Conselho nos demais Estados da Federação. 
${ }^{13} \mathrm{MePF} / \mathrm{INCRA} / \mathrm{MA} / \mathrm{SDr}$. (1999), Agricultura Familiar, Reforma Agrária e Desenvolvimento Local para um Novo Mundo Rural: política de desenvolvimento rural com base na expansão da agricultura familiar e sua inserção no mercado. Brasília, março.

\section{Referências bibliográficas}

Aridas. (1994), Projeto de Desenvolvimento Municipal Sustentável. Grupo VI — Projeto Áridas, Recife, dez.

BACELAR, Tânia. (1997), "Descentralização das ações de apoio à Reforma Agrária no Brasil: tendências e desafios", in INCRA/IICA, Descentralização das ações de apoio à Reforma Agrária. Recife: Anais do Seminário, nov.

BuARQue, Sérgio C. (1997), Globalização, desenvolvimento e Reforma Agrária, in INCRA/ICA, Descentralização das ações de apoio à Reforma Agrária. Recife: Anais do Seminário, nov.

BurszTyn, Marcel. (1998), "Introdução à Crítica da Razão Desestatizante". Revista do Serviço Público, ano 49, no 1, Brasília, jan./mar.

CAstells, Manuel. (1998), Hacia el Estado red? Globalización económica e instituciones politicas en la era de la información. São Paulo: MARE (Ponencia presentada en el Seminario sobre Sociedade y reforma del estado), mar., $16 \mathrm{p}$.

Contag. Descentralização da Reforma Agrária. documento interno, s/d., mimeo.

CuRAdo, Fernando F. (1998), Ocupação e assentamento na Fazenda Rio Vermelho: a constituição do agricultor assentado na região de Goiás. Dissertação (Mestrado em Desenvolvimento, Agricultura e Sociedade), Rio de Janeiro: UFRRJ/CPDA, 222p.

Dowbor, Ladislau. (1994), “Governabilidade e descentralização”. Revista do Serviço Público, no 1, Brasília, p. 95-117.

DraibE, Sônia M. (1993), “As políticas sociais e o neoliberalismo: reflexões suscitadas pelas experiências latino-americanas”. Revista da USP, São Paulo: USP, no 17, mar./ abr./maio.

Evans, Peter. (1993), “O Estado como Problema e Solução”. Revista Lua Nova, São Paulo, no $28 / 29$.

Furtado, Paulo e Goias, Jussara de. (1994), "Orçamento Público: desvendando a "caixapreta". Subsídio, Brasília: INESC, ano II, no 15, abr.

GARCIA, Jr. et al. (1997), “Assentamentos Rurais em perspectiva comparada: uma análise das dimensões econômica, social, histórica e ambiental". Debates CPDA, Rio de Janeiro, no 4, dez.

MEDEIROS, Leonilde S. de. (1994), Reforma agrária: concepções, controvérsias e questões. Rio de Janeiro: Rede Interamericana Agricultura e Democracia, jan.

OliveIRA, Edélcio Vigna de. (1997), "A razão entre Estado e a Agricultura Brasileira”. Informativo INESC, Brasília: INESC, no 79, out.

RoDRIGUEZ, Vicente. (1993), "A descentralização na educação: limites e possibilidades". Tempo e Presença, ํㅡㄹ 272, Rio de Janeiro: CEDI, dez.

Rosanvallon, Pierre. (1997), A Crise do Estado-Providência. Brasília: UFG/UnB.

Santos, Boaventura de Sousa. A Reinvenção Solidária e Participativa do Estado. Texto apresentado no Seminário Internacional Sociedade e a Reforma do Estado, s/d. mimeo. 
SouzA, Celina. (1998), "Dez anos de descentralização: a experiência dos municípios brasileiros", in FACHIN, Roberto \& CHANLAT, Alain (orgs.), Governo Municipal na América Latina: inovações e perplexidades. Porto Alegre: Sulina/Ed. da UFRGS.

Stein, Rosa H. (1997), A descentralização como instrumento de ação política: o caso da Assistência Social. Brasília. Dissertação (Mestrado em Política Social). Departamento de Serviço Social. Universidade de Brasília.

VIANNA JR., Aurélio. (1997), "O financiamento e a "inteligência": a importância das Instituições Financeiras Multilaterais do Brasil". Informativo INESC, Brasília: INESC, no 79 , out., p. 09 .

VIEIRA, Paulo Reis. (1971), Em busca de uma teoria de descentralização: uma análise comparativa em 45 países. Rio de Janeiro: FGV. 


\section{A descentralização da reforma agrária: algumas notas sobre o cenário brasileiro \\ Fernando Fleury Curado}

A temática da descentralização da reforma agrária vem ocupando nos últimos anos um espaço marcante no conjunto das proposições do Governo Federal para o campo.

A busca da delimitação deste assunto conduz à necessidade de identificação das leituras existentes acerca do Estado Moderno, efetivamente, à partir da crise do Estado de BemEstar Social. De um modo geral, tais leituras evidenciam, de um lado, a conformação de uma vertente neoliberal com a redução da presença do Estado, e, de outro, uma vertente progressista com a democratização do Estado a partir da multiplicação dos centros de poder e, conseqüentemente, da efetivação do controle local pelos seus usuários.

No terreno em que se sedimentam tais vertentes, a reflexão sobre a política de reforma agrária no país aponta para a existência de posições e interesses distintos e, muitas vezes, opostos entre os diferentes atores sociais envolvidos neste processo.

\section{La descentralización de la reforma agraria: algunas notas sobre el escenario brasileño \\ Fernando Fleury Curado}

El tema de la descentralización de la reforma agraria viene ocupando en los últimos años un espacio marcado en el conjunto de las propuestas del Gobierno Federal para el campo.

La búsqueda de la delimitación de este asunto conduce a la necesidad de identificar las lecturas existentes acerca del Estado Moderno, efectivamente, a partir de la crisis del Estado del Bien-Estar Social. De un modo general, tales lecturas evidencian, de un lado, la conformación de una vertiente neoliberal con la reducción de la presencia del Estado, y de otro, una vertiente progresista con la democratización del Estado a partir de la multiplicación de los centros de poder y consecuentemente, de la efectivación del control local por los usuarios.

En el ambiente en que se dan tales vertientes, la reflexión sobre la política de reforma agraria en el país apunta hacia la existencia de posiciones e intereses distintos y muchas veces, opuestos entre los diferentes actores sociales involucrados en este proceso.

\section{The decentralization of the agrarian reform: some notes on the Brazilian scene Fernando Fleury Curado}

The decentralization of the agrarian reform has been an issue of increasing discussion in the last few years as part of the Brazilian Federal Government's propositions for the rural environment.

The search of the delimitation of this subject leads to the need for identification of the present interpretations of the "Modern State", in particular, starting from the crisis of the "State of Social Well-being". These readings reveal on one side, the conformation of a neo-liberal view-point with the reduction of the presence of the State, and, on the other side, a progressive viewpoint with the democratization of the State, launched by the multiplication of the centres of power and, consequently, greater local control.

In such an environment, reflecting on the politics of agrarian reform in Brazil points to the existence of distinct positions and interests that are frequently opposite among the various social groups involved in this process.
Ano 53

Número 1

Jan-Mar 2002

Fernando Fleury Curado é mestre em Desenvolvimento Rural e doutorando em Meio Ambiente e Desenvolvimento pelo Centro de Desenvolvimento Sustentável da UnB.

Contato: fcurado@ uol.com.br 
A Revista do Serviço Público é uma publicação da ENAP Escola Nacional de Administração Pública, voltada para a divulgação e debate de temas relacionados ao Estado, à administração pública e à gestão governamental. Procurando o aprimoramento permanente da revista, tanto no seu conteúdo quanto na apresentação gráfica, pedimos aos nossos colaboradores a observação das normas abaixo descritas.

\section{Normas para os colaboradores}

1. Os artigos, sempre inéditos no Brasil, devem conter em torno de 25 laudas de 20 linhas de 70 toques.

2. Os originais devem ser encaminhados ao editor, em arquivo digital, em programa de uso universal e enviados para editora@enap.gov.br. Usar apenas as formatações-padrão.

3. Cada artigo deve vir acompanhado de um resumo analítico em português, espanhol e inglês, de cerca de 150 palavras, que permita uma visão global e antecipada do assunto tratado.

4. Na primeira página do artigo, deve constar informação sobre formação e vinculação institucional do autor (em até duas linhas).

5. Notas, referências e bibliografia devem vir ao final do artigo, e não ao pé da página. Notas e referências, sendo o caso, devem vir devidamente numeradas.

6. Além de artigos, a revista receberá comunicações, notas informativas, notícias e relatórios conclusivos de pesquisas em desenvolvimento, com até 15 laudas. Resenhas de livros, em torno de 4 laudas, devem conter uma apresentação sucinta da obra e eventuais comentários que situem o leitor na discussão.

7. Os trabalhos que se adequarem à linha temática da revista serão apreciados pelo conselho editorial, que decidirá sobre a publicação com base em pareceres de consultores ad hoc.

8. Os originais enviados à Revista do Serviço Público não serão devolvidos. A revista compromete-se a informar os autores sobre a publicação ou não de seus trabalhos.

\section{Convite a resenhadores}

A Revista do Serviço Público convida todos os interessados em remeter resenhas de trabalhos publicados no Brasil e no exterior sobre Estado, administração pública e gestão governamental.

As resenhas devem ser originais e não exceder a cinco laudas datilografadas em espaço duplo com 20 linhas de 70 toques, e devem apresentar de modo sucinto a obra, com comentários que situem o leitor na discussão apresentada.

As resenhas devem ser enviadas em português, sem notas de rodapé, contendo o título completo e subtítulo do livro, nome completo do autor, local de publicação, editora e ano de publicação, bem como uma breve informação sobre a formação e vinculação institucional do resenhador (em até duas linhas), acompanhadas do respectivo disquete.

\section{Nota aos editores}

Pedimos encaminhar à Revista do Serviço Público exemplares de livros publicados, a fim de serem resenhados. Os resenhadores interessados receberão cópias dos livros enviados. 
Cadernos ENAP

Números publicados

20 Metodologia para medir a satisfação do usuário no Canadá: desfazendo mitos e redesenhando roteiros

Geoff Dinsdale \& D. Brian Marson

Faye Schmidt \& Teresa Strickland — 2000

19 Experiências de Avaliação de Desempenho na Administração Pública Federal

Pesquisa ENAP - 2000

18 Reforma administrativa e relações trabalhistas no setor público Zairo B. Cheibub \& Richard M. Locke - 1999

17 Gerenciando a alta administração pública: uma pesquisa em países da OCDE

Organização de Cooperação e Desenvolvimento Econômico — 1999

16 Flexibilidade na gestão de pessoal da administração pública OCDE - Organização de Cooperação e Desenvolvimento Econômico - 1998

15 O processo decisório da reforma tributária e da previdência social Marcus André de Melo \& Sérgio Azevedo - 1998

14 Gerência de recursos humanos no setor público: lições da reforma em países desenvolvidos

Barbara Nunberg — 1997

13 Reforma do Estado no setor de saúde: os casos da Catalunha, Canadá, Reino Unido e Estados Unidos

Samuel Husenman \& Emili Sullà e outros — 1997

12 Normas de conduta para a vida pública Lord Nolan — 1997

11 A seguridade social no Brasil e os obstáculos institucionais à sua implementação

Pedro César Lima de Farias — 1997

10 O Impacto do modelo gerencial na administração pública Fernando Luiz Abrucio — 1997

9 Progressos recentes no financiamento da previdência social na América Latina

Manfred Nitsch \& Helmut Schwarzer — 1996

8 Reforma da Administração Pública e cultura política no Brasil Luciano Martins — 1997

7 Reforma do Estado

Evandro Ferreira Vasconcelos e outros — 1994

6 Planejamento e orçamento

Fábio Chaves Holanda e outros — 1994 
5 Recursos humanos no setor público

Marcelo Viana Estevão de Moraes e outros - 1994

4 A questão social no Brasil

Marcos Torres de Oliveira e outros - 1994

3 Gestão municipal e revisão constitucional

Luíza Erundina de Souza e outros - 1993

2 Cultura e memória na Administração Pública brasileira Iveraldo Lucena e outros — 1993

1 Gestão de recursos humanos, relações de trabalho e direitos sociais dos servidores públicos

Técnicos da ENAP e colaboradores — 1993 


\section{Texto para discussão \\ Números publicados}

45 A conceituação de governabilidade e governança, da sua relação entre si e com o conjunto da reforma do Estado e do seu aparelho Vinícius de Carvalho Araújo — março 2002

44 Reforma gerencial dos processos de planejamento e orçamento Fabiano Garcia Core - outubro 2001

43 Os Especialistas em Políticas Públicas e Gestão governamental: avaliação de sua contribuição para políticas públicas e trajetória profissional

Zairo B. Chaibub e Wânia Amélia Belchior Mesquita — agosto 2001

42 Experiências internacionais voltadas para a satisfação dos usuárioscidadãos com os serviços públicos

Pesquisa ENAP — maio 2001

41 Gestão de custos no setor público

Pesquisa ENAP — março 2001

40 Entre o público e o privado: O modelo de gestão de resíduos sólidos adotado pela SLU de Belo Horizonte

José Wanderley Novato Silva e Allan Claudius Queiroz Barbosa fevereiro 2001

39 A percepção das chefias sobre a capacitação nos cursos da ENAP Pesquisa ENAP — dezembro 2000

38 Perfil dos dirigentes de recursos humanos na Administração Pública Federal

Pesquisa ENAP — novembro 2000

37 Planejamento estratégico municipal no Brasil: uma nova abordagem Peter Pfeiffer - outubro 2000

36 Relatório de avaliação do curso Elaboração de indicadores de desempenho institucional

Pesquisa ENAP — outubro 2000

35 Modelo para informatização das administrações públicas municipais Maria José Ferreira Foregatto Margarido — agosto 2000

34 Perfil dos gestores de recursos humanos da Administração Pública Federal

Pesquisa ENAP — agosto 2000

33 A imanência do planejamento e da gestão: a experiência de Curitiba Luiz Carlos de Oliveira Cecílio, Carlos Homero Giacomini \& Miguel Ostoja Roguski — agosto 1999 
32 Sociedade civil: sua democratização para a reforma do Estado Luiz Carlos Bresser Pereira — novembro 1998

31 Custos no serviço público

Marcos Alonso Nunes — outubro 1998

30 Demissão por insuficiência de desempenho na reforma gerencial: avanços e desafios

Marianne Nassuno — setembro 1998

29 Reforma da previdência: negociações entre os poderes Legislativo e Executivo

Marcelo James Vasconcelos Coutinho — agosto 1998

28 Diagnóstico da situação da mulher na Administração Pública Federal

Franco César Bernardes, Marcelo Gameiro de Moura \& Marco Antônio de Castilhos Acco — julho 1998

27 Capacitação de recursos humanos no serviço público: problemas e impasses

Francisco Gaetani — junho 1998

26 Análise de macroprocessos na Secretaria de Recursos Humanos do MARE: uma abordagem sistêmica Marcelo de Matos Ramos — maio 1998

25 Desafios e oportunidades no setor de compras governamentais na América Latina e Caribe: o caso brasileiro

Carlos César Pimenta — abril 1998

24 Reconstruindo um novo Estado na América Latina Luiz Carlos Bresser Pereira — março 1998

23 Reforma administrativa e direito adquirido Paulo Modesto — fevereiro 1998

22 Utilizando a internet na administração pública Cláudio Seiji Sato — dezembro 1997

21 Burocracia, capacidade de Estado e mudança estrutural Tereza Cristina Cotta — novembro 1997

20 A reforma administrativa francesa: da crise da função pública a uma nova racionalidade da ação coletiva, uma difícil transição Valdei Araújo — outubro 1997

19 Formação e capacitação na construção de um novo Estado Evelyn Levy — setembro 1997

18 Agências Executivas: estratégias de reforma administrativa Marcos Alonso Nunes — agosto 1997 
17 Controle interno e paradigma gerencial Sheila Maria Reis Ribeiro — julho 1997

16 Novos padrões gerenciais no setor público: medidas do governo americano orientadas para o desempenho e resultados Bianor Scelza Cavalcanti \&Roberto Bevilacqua Otero — junho 1997

15 Cidadania e Res publica: a emergência dos direitos republicanos Luiz Carlos Bresser Pereira — maio 1997

14 Gestão e avaliação de políticas e programas sociais: subsídios para discussão Francisco Gaetani — abril 1997

13 As escolas e institutos de administração pública na América Latina diante da crise do Estado Enrique Saravia - março 1997

12 A modernização do Estado: as lições de uma experiência Serge Vallemont — dezembro 1996

11 Governabilidade, governança e capacidade governativa Maria Helena de Castro Santos — dezembro 1996

10 Qual Estado? Mário Cesar Flores — novembro 1996

9 Administração pública gerencial: estratégia e estrutura para um novo Estado Luiz Carlos Bresser Pereira — outubro 1996

8 Desempenho e controle na reforma administrativa Simon Schwartzman — setembro 1996

7 Brasil século XXI - A construção de um Estado eficaz Virginio Augusto Ferreira Coutinho \& Maria Teresa Oliva Silveira Campos — agosto 1996

6 A tecnologia da informação na reforma do Estado Ricardo Adolfo de Campos Saur — julho 1996

5 Reforma administrativa e direito adquirido ao regime da função pública Paulo Modesto — outubro 1995

4 Estado, aparelho do Estado e sociedade civil Luiz Carlos Bresser Pereira — outubro 1995

3 Reflexões sobre a proposta da reforma do Estado brasileiro Gleisi Heisler Neves — outubro 1995

2 A questão da estabilidade do serviço público no Brasil: perspectivas de flexibilização Érica Mássimo Machado \& Lícia Maria Umbelino — julho 1995

1 A reforma do aparelho do Estado e a Constituição brasileira Luiz Carlos Bresser Pereira — maio 1995 
Solicitação de publicações

Nome/Instituição:

CPF/CNPJ:

Endereço:

Cidade:

UF:

CEP:

Telefone:

Fax:

E-mail:

Cartão de assinatura da RSP

Periodicidade: trimestral

Assinatura anual: $\mathrm{R} \$ 40,00$

口 Ano 53-2002

口 Número avulso: R\$12,00 Ediçãon $n^{\circ}$

口 Exemplar avulso anterior a 1997: R \$ 8,00

\section{Cadernos ENAP}

\begin{tabular}{lllllllll}
\hline$\square 4$ & $\square 5$ & $\square 6$ & $\square 7$ & $\square 8$ & $\square 9$ & $\square 10$ & $\square 11$ & $\square 12$ \\
$\square 13$ & $\square 14$ & $\square 15$ & $\square 16$ & $\square 17$ & $\square 18$ & $\square 20$ & &
\end{tabular}

Preço unitário: $R \$ 10,00$

Texto para discussão

\begin{tabular}{|c|c|c|c|c|c|c|c|c|c|}
\hline 口1 & $\square 2$ & $\square 3$ & प & 口 & व6 & a & $\square 8$ & 9 & 10 \\
\hline 口11 & 12 & $\square 13$ & $\square_{14}$ & 15 & $\square 16$ & 口17 & $\square 18$ & 19 & $\square 20$ \\
\hline$\square 21$ & 22 & $\square 23$ & $\square 24$ & D25 & $\square 26$ & $\square 27$ & $\square 28$ & ב29 & $\square 30$ \\
\hline 口31 & 口32 & 口33 & 口34 & 口35 & 口36 & 口37 & $\square 38$ & 口39 & $\square 40$ \\
\hline 口41 & 42 & $\square 43$ & $\square 44$ & 口45 & & & & & \\
\hline
\end{tabular}

Números 1 ao 5: $R \$ 3,00$

A partir do número 6: $R \$ 5,00$

Forma de pagamento ver orientação no verso

Cheque nominal $\square$ Ordem de pagamento $\square$ Nota de empenho 
Forma de pagamento

- Cheque nominal à ENAP Fundação Escola Nacional de Administração Pública.

- Ordem de pagamento (anexar cópia do comprovante de depósito) em nome da ENAP Escola Nacional de Administração Pública, através do Banco do Brasil S/A, Agência Ministério da Fazenda 3602-1, Conta Corrente: 170500-8 Depósito identificado (código - dv) finalidade: 11470211401002-2.

- Nota de empenho em nome da ENAP Escola Nacional de Administração Pública (anexar original). (UG:114702, Gestão: 11401).

ENAP Escola Nacional de Administração Pública

Diretoria de Informação e Conhecimento em Gestão

SAIS - Área 2-A

70610-900-Brasília, DF

Tel:(61) 445 7096/445 7102—Fax:(61) 4457178

CNPJ:00627612/0001-09

Site: www.enap.gov.br

E-mail:publicacoes@enap.gov.br 